\title{
EFFECTIVNESS OF WASTE MINIMISATION PROJECTS IN REDUCING WATER DEMAND BY UK INDUSTRY.
}

\section{C.P. Holt, P.S. Phillips and M.P. Bates.}

\begin{abstract}
There is growing interest in managing water demand in the UK. A series of waste minimisation clubs have been set up within the country and this paper identifies the effectiveness of these clubs in reducing the demand for water within industry. Membership of these clubs is voluntary and the only incentive for industry to reduce water consumption, and consequently the production of effluent, is the almost immediate financial saving made by the company, often achieved by accounting for the water consumption and loss within site from the point of input from the water supplier to output in the form of effluent. On average, companies are able to reduce water consumption by up to $30 \%$. If the entire industrial sector within the UK were to achieve this degree of saving, it is possible that approximately $1300 \mathrm{Ml} / \mathrm{d}$ could be saved.
\end{abstract}

Key Terms: Water use minimisation, water demand, waste minimisation, water management, industrial water conservation.

\section{Introduction:}

Within the UK there has been an increasing drive towards water conservation, due, in part, to a sequence of droughts that have affected most of the UK since the mid 1970s. The privatisation of the water supply industry in England and Wales, 
combined with pressure from the Environment Agency (EA), Office of Water Services (OFWAT), the Government and consumers has encouraged greater expenditure on the reduction of water wasted in the distribution network through leaks. The financial savings that can result from reducing water consumption in the industrial sector has started to encourage some companies to actively seek measures to cut water requirements.

Demand for water in England and Wales increased rapidly during the 1960s and 1970s, although the rate of growth in demand declined during the 1980s (NRA, 1992a), due to a dramatic change in economic conditions and a shift away from traditional heavy industry. An estimated $17,300 \mathrm{Ml} / \mathrm{d}$ of water was put into the public supply during 1990 (WSA, 1991), of which an assumed 25\% was lost via leakage or was classified as unaccounted for. Of the total input, $5,850 \mathrm{Ml} / \mathrm{d}$ was consumed by the commercial, industrial and agricultural sectors (WSA, 1991). The Water Services Association (WSA) estimated that $55 \%$ of the water put into supply was taken by domestic users, $5 \%$ by agriculture, $15 \%$ by commercial and the service sector, with the remaining $25 \%$ being consumed by industry (WSA, 1991). Reduction of the amount of water lost through leakage has been seen as a major advance in sustaining water resources, with total leakage falling by $475 \mathrm{Ml} / \mathrm{d}$ between 1995 and 1997 (OFWAT, 1997). It has been estimated that regional demand will have increased by 2021, with only North West Water experiencing an approximate $10 \%$ decline in demand (Figure 1). The existing water gathering infrastructure will therefore be placed under increasing pressure to meet this new demand, unless new resources are brought on line and/or the rise in demand is checked or limited. 
By 2021, it is anticipated that south east England will be in a situation of parity between available resources and demand, while the Anglian region will have a 4\% shortfall (NRA, 1992b). Western areas will potentially have a slight surplus, with the $25 \%$ surplus of resources over demand in Wales being the greatest (Figure 1). Under normal climate conditions, this will not really cau se any significant problems, with the exception of the Anglian region. Unless water is used more efficiently in those areas that could experience parity between demand and available supplies, there could be a restrictions on further industrial/commercial development.

Climate change may lead to a significant change in the reliability of individual supply sources, although it is difficult to quantify the potential reduction. It has been suggested (eg Arnell, 1998) that it is over a longer time scale that the impact of climate change will be felt as opposed to in the immediate future. In Wales, it is possible that an overall reduction of $20 \%$ in the operational yields of reservoirs could occur by 2100 (Holt and Jones, 1996). From a wider perspective, the current climate provides $2,650 \mathrm{~m}^{3} / \mathrm{yr}$ of water per person in the UK, with around $1,000 \mathrm{~m}^{3} / \mathrm{yr}$ being considered (Engelman and LeRoy, 1993) the level below which water scarcity and hence water stress begins. Based on the present population growth, water availability will drop to $2,430 \mathrm{~m}^{3} / \mathrm{yr}$ by 2050 , although if climate change is also taken into account then the range for 2050 would be between 2,190 and 2,520m³/yr (Kaczmarek, 1996).

\section{The UK wastes management strategy}


The common practice of waste management, in the UK, has been either to recycle, treat or dispose of waste at the end of a process (Gray, 1997). However, these are the least desirable ways of dealing with the problem. Ideally, it would be most environmentally acceptable to eliminate completely the generation of liquid or solid wastes. This may be an unobtainable target in every case and so attention needs to be placed upon minimising the generation of waste at source. Waste minimisation is near the top of almost every version of a waste management hierarchy and is considered to be an important management technique to conserve scarce resources, such as water. The waste hierarchy is:

1. Elimination of waste;

2. Waste minimisation or source reduction;

3. Reuse;

4. Recycling;

5. Treatment;

6. Disposal.

Elimination of water wastage, in the UK, has of ten occurred via the introduction of extensive metering of all process flows. This enables an accurate mass balance to be determined and water loss, via leakage, can be detected and prevented. Waste minimisation developments have concentrated upon reducing the amount of water used in industry by process optimisation. The adoption of improved methods of treatment, e.g. membrane separation, has resulted in opportunities to reuse and recycle water and so reduce effluent production. 
Waste minimisation is the broad term used for a variety of measures that conserve resources through the reduction of the amount of raw materials used to produce a given unit of product. It will mean different things to different people and groups, of ten synonymous with a reduction in the amount of material used to make a product or, mistakenly, with a reduction of the amount of waste destined for final disposal (INCPEN, 1995).

The UK Environment Agency describes waste minimisation (Environment Agency, 1997) as:

The reduction of waste at source, by understanding and changing processes to reduce and prevent waste. This is also known as process or resource efficiency. Waste minimisation also includes the substitution of less environmentally harmful materials in the production process.

From a range of national definitions, a composite working definition has been produced (IWM, 1996), it is: "Prevention and / or reducing the generation of waste, improving the quality of waste generated, including reduction of hazard and encouraging re-use, recycling and recovery."

There is still a need to develop an overall clear definition of waste minimisation that will be subscribed to by a range of agencies and that can be used in a wide variety of contexts in the UK, especially water management. Notwithstanding this, a significant number of publications have been produced extolling the benefits of waste minimisation to the commercial / industrial as well as the domestic sector for liquid 
and solid wastes. These include topics such as: saving money (ETBPP, 1996a), environmental benefits (ETBPP, 1996b) and increasing quality (ETBPP, 1996c). A wide range of organisations have produced guides for all sectors. These include: the Institute of Chemical Engineers (1992), the Ceramics Industry (British Ceramic Confederation, 1994). As the subject progresses, more information is coming to light on topics such as: barriers to improved environmental performance ( e.g. ETBPP, 1996d) and teams and project champions (e.g. ETBPP, 1996e).

Waste minimisation techniques have found application in a wide range of industries that formerly produced large volumes of high strength waste waters (Gupta, 1994) and the adoption of clean technology by such industries have also been promoted (Clift, 1995). Smaller scale waste water producers such as the meat-production industry has also recognised the need to introduce wastes minimisation (Johns, 1995). Waste minimisation strategies applied to industry have resulted in advantages for local river basin management (Edwards et. al, 1997) and improved the prospects for long term sustainability for the management of water resources (Tyson, 1995).

There is a need to bolster and promote the waste hierarchy so that more emphasis is placed upon minimisation. Limitations and issues need further investigation, particularly the hierarchy's applicability and use for local authorities concerning domestic waste (Wilson, 1995). In some cases the hierarchy must be viewed only as a guide to find the best practical environmental option. The possible financial benefits for companies need also to be stated more carefully and perhaps conservatively. It has been shown (e.g. Johnston and Stokes, 1995) that annual first year savings, on average, are around $0.27 \%$ of turnover and that assuming the cost of 
implementing is around $£ 6000$, companies with less than $£ 2.2$ million turnover may not consider the effort to be beneficial. Productivity needs to be considered in more sophisticated environmental terms (Chung et. al, 1997) and new methods need to be developed for analysing waste management systems (Chang and Wang, 1996).

The White Paper of 1995, Making Waste Work: A strategy for sustainable waste management in England and Wales (HMSO, 1995), is a comprehensive statement clarifying the position of the UK Government. This paper develops the ideas put forward in the Government's earlier publication in 1994, Sustainable Development: The UK strategy (HMSO, 1994). The White Paper emphasises the role of key stakeholders in driving forward the agenda. A pivotal role has been proposed for Central Government, as well as industry and local authorities.

Making Waste Work encourages industry to adopt better waste management practices as well as ensuring that its products are designed to take into account the objective of sustainable development. Industry is challenged to meet a range of targets and to move towards a greater emphasis upon waste minimisation. These targets include: $75 \%$ of companies with more than 200 employees to have published environmental policies covering waste by the end of 1999 and $50 \%$ of similar sized concerns to have management system in place to realise such policies in the same time scale.

The contribution of the Government is underpinned by the activity of several agencies, including the Environmental Technology Best Practice Programme (ETBPP) and the Environment Agency. Extensive advice is available to companies on environmental matters from local Green Business Clubs who are connected to County 
based Business Links. The privatised utilities are also very active in resource efficiency programmes, especially water companies.

The ETBPP provide a wide range of appropriate literature to inform companies on resource efficiency as well as offering free audits for Small to Medium Enterprises (SME's). The ETBPP has a central role in the development and operation of regional waste minimisation project clubs to which they contribute resources and expertise. These clubs, they of ten last for 1 to 2 years, can act as demonstration projects whereby local industry can learn of the benefits, of conserving resources, by observing them function in a local setting.

There have been approximately 60 such clubs in the UK and some of the more successful include; Aire and Calder, Dee, Humber Forum, Project Catalyst and Leicester (Figure 2 and Table 1 ). The Aire and Calder Project was launched in 1992 in response to the recognised need to demonstrate the benefits of resource efficiency to local companies (Johnston, 1995). The Rivers Aire and Calder drain densely populated and industrial catchments in West Yorkshire. The river systems have experienced a long history of serious water pollution. Water management was a central component of this project which aimed to:

- $\quad$ reduce demand for water - local abstractions have had serious impacts on ground water level;

- $\quad$ reduce effluent production; 
- $\quad$ identify the means of reducing the risk of accidental pollution.

The local water company - Yorkshire Water - had a particular interest in the project as results concerning reduced usage of water would enable them to better model their likely requirements for future needs.

In their consultation document, Wastes Management and Regulation Strategy (Environment Agency, 1996), the Environment Agency has outlined aspects of its future role. This Agency is one of the most powerful environmental regulators in the world. It provides a comprehensive approach to the protection and management of the environment by combining the regulation of land, air and water.

The Agency is developing, over five years, Local Environmental Agency Plans (LEAPs) to integrate delivery of their regulatory and environmental management functions at the local level. They monitor river flows, groundwater levels, rainfall and climate to assess the available water resource. Officers regulate abstraction by issuing and enforcing licences granted to industrial interests. They aim to effectively manage the water resources of a LEAP area - normally a river basin - in a sustainable manner, to achieve secure water supplies for abstractors and a better water environment for future generations.

The Agency acknowledges that their role in Waste Regulation requires:

The proper management of wastes, so as to reduce their overall impact on the environment, is essential to the environmental and economic well being of our society 
and its sustainable development in the future. This will be achieved by developing strategies for the reduction, reuse, recycling and safe disposal of wastes and by encouraging the adoption of these by society.

The Environment Agency is playing a central role in wastes minimisation by helping develop and run regional wastes minimisation clubs. They, as regulators, are in a unique position to draw together, into a functioning group, the many separate organisations that are required for a successful project.

\section{Wastes Minimisation Methodology}

A wastes minimisation programme delivers short and long term benefits in four ways:

- Cost saving - this is achieved by increased operating efficiency and reduction in production costs;

- $\quad$ Competitive advantage - cost reductions and improved company image;

- $\quad$ Regulatory compliance;

- $\quad$ Risk reduction.

The overall methodology, adopted in the Aire and Calder Project and in many others in the UK, is shown in Figure 3. 
The waste audit is the central component of a successful wastes minimisation project. The waste audit commences with the process review, which is the key level of analysis and understanding of the whole audit. Process flow diagrams are constructed for each process occurring in a company. Complex programmes are broken down into component activities so that a process model can be produced (Figure 3 ). This flow diagram allows the identification of potential and actual waste streams and enables quantitative information to be gathered. The critical activity here is one of monitoring to establish what the base line is before the systematic programme to minimise waste. Once the programme starts then improvements in process efficiency can be planned.

Water usage and cost are key elements of any process model. Companies should have historical figures for consumption of water. This may be broken down into accountable sub-units such as production departments to aid in the preparation of the first wastes minimisation target figures. Often, companies have incomplete historical records and insufficient metering to enable accurate process models to be determined, they will then have to install a considerable number of meters to produce accurate data from which to work. Effluent generation and costs must also be determined. As the costs are related to several parameters it is essential that a company regularly monitors the volume and characteristics of their effluent. A well designed process model with accurate inputted data enables many companies, in the UK, to reduce water consumption by between 10 and $50 \%$, with similar reductions in effluent. The total financial savings are can be in the order of $0.2 \%$, or greater, of turnover with markedly improved environmental indicators. 


\section{Results and Discussion.}

There is a financial incentive for companies to reduce their water consumption, however, it has been noted (ETBPP, 1996f) that prior to the initiation of a programme to reduce both water consumption and the production of waste water, the true costs have rarely been calculated. Usually a company will only have a general idea of the cost of water supply and disposal, and often falls into the trap of underestimating this cost and hence the potential savings that could be made by pursuing a policy of water use minimisation.

The financial cost and savings, together with the potential and actual water savings from eight waste minimisation clubs is summarised in Table 1. Due to the lack of standardisation in the reporting of water savings, it is impossible to obtain a complete set of values for all projects. By reducing the amount of water consumed, the companies are making financial savings in two major sectors; the cost of water coming into the site is reduced, and due to this the amount of effluent produced declines. Due to this two point saving combined with the financial saving brought about by reducing solid waste, the schemes tend to produce a very rapid return on the initial investment. The Dee Waste Minimisation Club has the greatest return with the total financial saving made by reducing water use, solid and liquid waste, exceeding the initial cost of the project by over twenty times in a single year (Table 1). The Dee scheme is particularly effective as the financial return is normally much lower, but it still tends to be more than double the initial investment. Of particular note is the 
usually large discrepancy between the potential and implemented reductions (Table 1). The Dee project club has implemented a reduction in the amount of water consumed amounting to almost $80 \%$ of the potential savings identified, which is in sharp contrast to the $11 \%$ achieved by Humber and WEFT. In part this is a reflection of the Dee project being set up primarily to reduce water consumption, but at the same time it identifies the inability or unwillingness of companies to modify production procedure or technology to take advantage of the potential water savings.

The Leicester Waste Minimisation Club comprises ten companies, one of which is Everards Brewery. The cost of raw materials makes up only a small proportion of the company's financial output. The bulk of which is for paying the water bill, since large quantities of water are required to produce the beer and for cleaning, resulting in a large financial outlay to cover effluent charges (Table 2).

In order to identify the areas where savings in water consumption could be made, a more detailed water balance was produced (Table 3 ). There is a small difference between water input and output as effluent which represent about $90 \%$ of the water coming into the system. The process of brewing will entail water loss via the end product, although the production process itself also involves some losses, primarily through evaporation and during boiling off. The total loss during the production of the end product is almost $18 \%$ of the water brought into the system, as a result, the output effluent should be only $51,168 \mathrm{~m}^{3} \mathrm{pa}$ instead of the $55,704 \mathrm{~m}^{3} \mathrm{pa}$ produced by the water budget (Table 3). This clearly shows the importance of considering rain water which is normally disposed of via the drainage system on the premises, which automatically increases the effluent bill if the rain water is directed to the foul sewer. 
By following the production process from start to finish, and quantifying the varying water inputs/outputs during the production process it is possible to identify processes that are losing water. Occasionally a water budget can identify discrepancies between the metered input and output. At Everards Brewery an unexplained input of $305 \mathrm{~m}^{3}$ of water during a single year (Table 3) was discovered, consequently effluent discharge was elevated. By locating the source of the additional water input and preventing the water from entering the system, it is possible to make a financial saving through reduced effluent charges.

Following the completion of a company specific water budget, the next stage in water minimisation is the production of an action plan (Table 4). Some of the water savings identified by the survey require capital investment, and hence would only be implemented when the existing equipment was at the end of its economic life. Changes in production that have an immediate impact, without major restructuring, tend to be implemented fairly rapidly, although there is still a significant discrepancy between the target set for savings and the savings achieved to date (Table 4).

Within the UK, there is an imbalance between water resources and demand. Most of the current surplus is in the west and north of the country, with the south east experiencing a resource deficit. This situation is predicted to worsen in the future, with demand in England and Wales projected to increase by $18 \%$ or approximately an additional $3200 \mathrm{Ml} /$ day by 2021 (NRA, 1992b), with over three quarters of this increase in demand anticipated from the south and east of the country (Arnell et. al, 1994). Several methods have been proposed to redress this resource imbalance, including demand management and groundwater development, both of which are 
considered low cost options by the Environment Agency, costing between $£ 0.1$ and $0.5 \mathrm{million} / \mathrm{Ml} /$ day (NRA, 1992b). Other options that are likely to be implemented include, re-use of effluent and a programme of reservoir building, which will be more costly with an indicative cost of between $£ 0.5$ and 2.5 million/Ml/day (NRA, 1992b). Another proposal to remedy the resource imbalance is the implementation of interregional transfers, although the cost of some of the larger projects would exceed $£ 2$ million/Ml/day (NRA, 1992b). The more expensive inter-regional transfer schemes include a proposal to transport water from the mid-Cambrian area of Wales to southeast England. From a cost perspective, demand management and groundwater development are the least expensive to implement.

Demand management is potentially the most beneficial of approaches that can be implemented to redress the resource/demand imbalance on both spatial and temporal scales. This approach has an additional incentive in that it can be rapidly implemented, and the savings in terms of a reduction in water consumption is visible within a year of implementing water savings within the company. The waste minimisation clubs have been shown to reduce actual water consumption by an average of $30 \%$, although this does mask considerable variation. With daily demand expected to increase to an additional $3200 \mathrm{Ml} /$ day by 2021 (NRA, 1992b), the average reduction in demand of $30 \%$ would be very significant if all companies adopt a water use minimisation strategy. An average saving of $30 \%$ would result in a reduction in demand of approximately $1300 \mathrm{Ml} /$ day. It is important to note that this saving, currently, only applies to those companies that actually participate in the projects. In Northamptonshire, only 22 out of approximately 18,000 companies are currently participating in the waste minimisation club, a take up of only $0.12 \%$. Since demand 
management is considered the first step before developing new resources (NRA, 1992a), the fact that only a small proportion of companies join waste minimisation clubs combined with the large gap between potential water savings and those savings implemented by most companies indicates that there is a lot of work required in the UK to persuade companies to make more efficacious use of water. The inefficiency of companies in the UK to reduce water consumption is put into perspective when the reduction in water use per unit of production for the pulp and paper, chemical, chemical and steel industries by an average of $50 \%$ is taken into consideration for the period between 1954 and 1978 in the USA (David, 1984). Part of this decline has been attributed (David, 1984) to the 1972 Clean Water Act which restricted the discharge of untreated wastewater, the implication of which was that if companies have to treat wastewater before discharging it, there is a tendency to reduce the amount of water taken from the supply network and to re-use more of it where appropriate. In the UK, companies do have a financial incentive to reduce consumption and discharge of water, since both cost the company money. However, any change in the price of either supply or effluent treatment has a limited impact on the demand. Potentially, this is due to a combination of factors, including the fact that there are no suitable substitutes for water to which companies could switch and that the cost of water is low enough to remove most of the incentive for companies to monitor consumption rates and/or change the amount of water consumed should prices change (Chesnutt and Beecher, 1998). Other studies (e.g. Loaiciga and Renehan, 1997) suggest that the reduction in the consumption of water can be achieved through using multi-approach techniques involving the pricing of water, water conservation measures backed by enforcement and changes in consumer behaviour. Although, Loaiciga and Renehan (1997) in their study of water 
consumption in Santa Barbara, California over a ten year period concluded that it was difficult to determine how much of the decline in water consumption was due to water pricing and how much to conservation measures.

\section{Conclusions}

Industry, if it adopts water saving technology and strategies, can make significant financial savings over a time scale of only a year due to the cut in water consumption by an average of $30 \%$. With increasing demand in the UK, in particular in those regions where supply currently exceeds demand by a small proportion, demand reduction will be particularly significant when considering the future water budget of the region. If the uncertainty of global warming is taken into account, the current models suggest that the south east of the UK will become drier, which places increased pressure on the supply in that region. There is an increasing likelihood of a water shortfall in the south east of the UK, which is an area containing a high population, combined with significant demands for water from both the agricultural and industrial sectors.

The water industry can solve the potential water shortfall via one of three approaches. More reservoirs could be constructed, water could be transferred from those areas of the UK with a large water surplus (generally the northern and western regions), or demand could be actively managed. The last option would be less costly to implement, and the results would become apparent soon after implementation. For the demand management approach to have any significant effect, more companies 
will have to opt into the currently optional waste minimisation clubs. Domestic consumption could also be reduced by actively pushing water efficiency in the home, although since most of the houses in the UK are not metered, the effectiveness of this policy is not likely to be as great as in other European countries. Despite the low numbers of companies joining waste minimisation clubs in the UK, the fact that the schemes are voluntary does increase the scale of their achievement, however the fact that water minimisation within the UK still has a long way to go must not be forgotten. 


\section{Literature Cited:}

Arnell, N.W. (1998): Climate change and water resources in Britain. Climatic Change, 39, 83-110.

Arnell, N.W., Jenkins, A. and George, D.G. (1994): The Implications of Climate

Change for the National Rivers Authority. NRA R\&D Report 12, HMSO, London, $94 \mathrm{pp}$.

British Ceramic Confederation (1994): Waste Minimisation: A Guide for the Ceramics Industry. British Ceramic Confederation, Stoke-on-Trent UK.

Chang, N. B. and Wang, S.F. (1996): Solid Waste Management System Analysis by Multiobjective Mixed Integer Programming Model. Journal of Environmental Management. 48:17-43.

Chesnutt, T.W. and Beecher, J.A. (1998): Conservation rates in the real world. Journal of the American Water Works Association. 90(2), 60-70.

Chung, Y.H., Fare, R. and Grosskopf, S. (1997). Productivity and Undesirable Outputs: A Directional Distance Function Approach. Journal of Environmental Management. 51:229-240. 
Clift, R. (1995): Clean technology - an introduction. Journal of Chemical Technology and Biotechnology, 62(4), 321-326.

David, E.L. (1984): A quarter century of industrial water use and a decade of discharge controls. Water Resources Bulletin, 20(3), 409-416.

Edwards, A.M.C., Freestone, R.J. and Crockett, C.P. (1997): River management in the Humber catchment. Science of the Total Environment, 194, 235-246.

Engelman, R. and LeRoy, P. (1993): Sustaining Water: Population and the future of renewable water supplies. Population Action International, Washington D.C., 56 pp.

Environment Agency (1996): Waste Management \& Regulation Strategy. Environment Agency, Lincoln UK.

Environment Agency (1997): Waste Minimisation and Waste Management, 1997. An Environmental Good Practice Guide for Industry. Environment Agency, Solihull UK.

Environmental Technology Best Practice Programme (1996a): Saving Money Through Waste Minimisation: Raw Material Use. ETBPP, Didcot UK.

Environmental Technology Best Practice Programme (1996b): Environmental Improvements Reduce Costs. ETBPP Case Study GC59. ETBPP, Didcot UK. 
Environmental Technology Best Practice Programme (1996c): Increasing Quality and Profits by Designing Out Waste. ETBPP Case Study CH64. ETBPP, Didcot UK.

Environmental Technology Best Practice Programme (1996d): Attitudes and Barriers to Improved Environmental Performance. ETBPP, Didcot UK.

Environmental Technology Best Practice Programme (1996e): Saving Money Through Waste Minimisation: Teams and Champions. ETBPP Good Practice Guide GG27, Didcot UK.

Environmental Technology Best Practice Programme (1996f): Saving Money Through Waste Minimisation: Reducing Water Use. Environmental Technology Best Practice Programme. 17pp.

Gray, J.M. (1997): Environment, policy and municipal waste management in the UK. Transactions of the Institute of British Geographers, 22: 69-90.

Gupta, P.K. (1994): Environmental management in the agro-based pulp and paper industry in India - a holistic approach. Water Science and Technology.30(3), 209215.

HMSO (1994): Sustainable Development: The UK strategy. HMSO, London UK.

HMSO (1995): Making Waste Work: A strategy for sustainable waste management in England and Wales. HMSO, London UK. 
Holt, C.P. and Jones, J.A.A. (1996): Sensitivity analyses for the impact of global warming on water resources in Wales. In: Jones, J.A.A., Liu, C., Woo, M.K. and Kung, H.T. (eds.): Regional Hydrological Response to Climate Change. Kluwer, Dordrecht. pp. 317-335.

Industry Council for Packaging and the Environment (1995): Waste Minimisation Factsheet. INCPEN, London UK.

Institute of Chemical Engineers (1992): Waste Minimisation Guide. Institute of Chemical Engineers, Rugby UK.

Institute of Wastes Management (1996): Waste Minimisation. Institute of Wastes Management, Northampton UK.

Johns, M.R. (1995): Developments in waste water treatment in the meat processing industry - a review. Biosource Technology, 54(3), 203-216.

Johnston, N. (1995): Final report on the Aire and Calder Project. Centre for Exploitation of Science and Technology, London.

Johnston, N. and Stokes, A. (1995): Waste Minimisation and Cleaner Technology. An Assessment of Motivation. Centre for Exploitation of Science and Technology, London UK. 
Kaczmarek, Z. (1996): Water Resources Management. In: Watson, R.T., Zinyowera, M.C. and Moss, R.H. (eds.): Climate Change 1995. Impacts, adaptations and mitigation of climate change: Scientific-technical analyses. Cambridge University Press. 469-486.

Loaiciga, H.A. and Renehan, S. (1997): Municipal water use and water rates driven by severe drought: A case study. Journal of the American Water Resources Association. 33(6), 1313-1326.

National Rivers Authority (1992a): Sustaining our Resources. Southern Region water resources development strategy. NRA Southern Region, Worthing.

National Rivers Authority (1992b) Water Resources Development Strategy. A Discussion Document. NRA, Bristol. 12pp.

OFWAT (1997) 1996-97 Report on leakage and water efficiency. OFWAT, Birmingham. 43pp.

Tyson. J.M. (1995): Quo Vadis - sustainability. Water Science and Technology, $32(5-6), 1-5$.

Wilson, D.C. (1995): How best to move waste management up the hierarchy; stick or carrot?. Institute of Wastes Management Conference Proceedings, 76-81.

WSA (1991): Waterfacts 1991. Water Services Association, London. 
Figure 3. Waste Minimisation Methodology

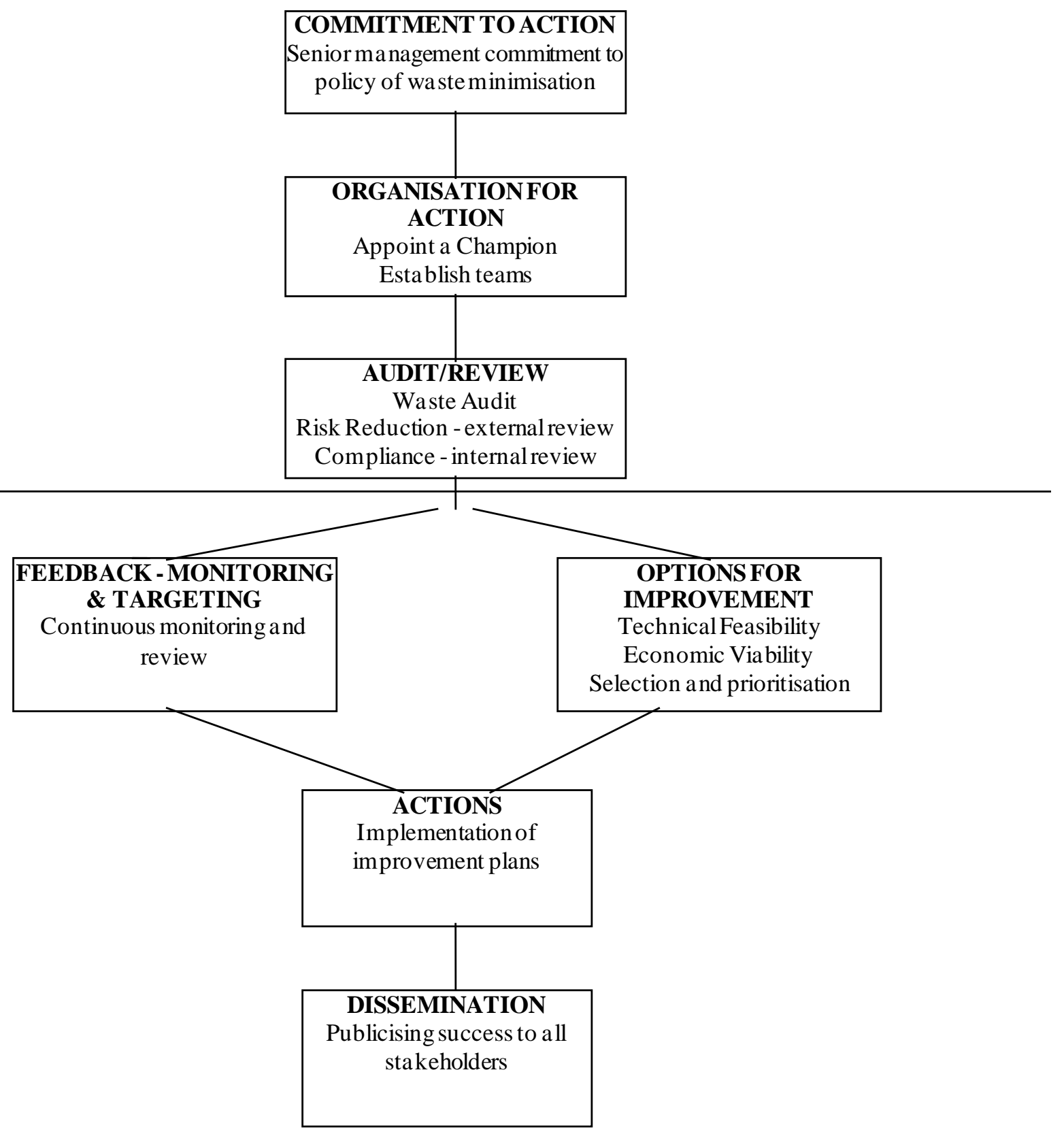


Table 2: Summary of waste costs at Everards Brewery

\begin{tabular}{cc}
\hline Area of Loss & Value (£’000s) \\
\hline Keg beer - yield loss & 22 \\
Cask beer - yield loss & 26 \\
Factored - yield loss & 17 \\
Water for cleaning & 28 \\
Effluent & 58 \\
Waste skips & 2 \\
$\mathrm{CO}_{2}$ loss & 13 \\
\hline Total Cost of Waste & 166 \\
\hline
\end{tabular}


Table 3 Water balance for Everards Brewery

(Values in brackets denotes losses from the system)

\begin{tabular}{lcc}
\hline & $\mathrm{m}^{3} \mathrm{pa}$ & $\%$ \\
\hline Input (consumption) & 62,249 & 100 \\
\hline Rain water & 4,234 & 6.8 \\
Steam evaporation & $(1,560)$ & $(2.5)$ \\
Boiled off ( during & $(734)$ & $(1.2)$ \\
brewing) & & \\
In spent grain & $(509)$ & $(0.8)$ \\
Shipped in product & $(8,280)$ & $(13.3)$ \\
Unexplained & 305 & $(0.5)$ \\
\hline Output (effluent) & 55,704 & 89.5 \\
\hline
\end{tabular}


Table 4 Action Plan for Everads Brewery.

$\begin{array}{ccc}\text { Target } & \text { Achieved } & \text { Capital } \\ \text { Savings } & \text { Savings } & \text { Investmen } \\ (£ ’ 00 s) & (£ ' 000 s) & \text { t Required }\end{array}$

Yield Improvement

Monitor and publish brewing yields

Agree \& implement accurate method

of reading tank contents

Check cask filling tubes for seepage

Investigate $\&$ correct yeast fob

return system

Cleaning Water Consumption

Improve monitoring of water

consumption

Add meters to brewing \& process

areas

Fit timers to cleaning system

Reduce water flow to process

cleaning system

Reduced timed cleaning cycle for

bright beer tanks

Develop better method of cleaning

yeast tanks

Yes

Yes

$8-1$

\section{Effluent}

Collect spillage at cask filling

Resolve rain/drain problem

20

Yes

Re-use "spent" cleaning water where possible

$\mathrm{CO}_{2}$

\section{General}

Produce waste monitoring system

Monitor results and follow-up

\section{Total - 13 projects}


Table 1: Waste Minimisation project with potential and actual water savings.

\begin{tabular}{|c|c|c|c|c|c|c|}
\hline \multirow{2}{*}{$\begin{array}{c}\text { Project } \\
\text { Dee }\end{array}$} & \multirow{2}{*}{$\begin{array}{c}\begin{array}{c}\text { Cost } \\
(£ ' 000)\end{array} \\
200\end{array}$} & \multirow{2}{*}{$\begin{array}{c}\begin{array}{c}\text { Number of } \\
\text { companies }\end{array} \\
13\end{array}$} & \multicolumn{2}{|c|}{$\begin{array}{l}\text { Liquid effluent reduction } \\
\qquad\left({ }^{\circ} 000 \mathrm{~m}^{3}\right)\end{array}$} & \multicolumn{2}{|c|}{$\begin{array}{c}\text { Savings of water } \\
\left({ }^{\circ} 000 \mathrm{~m}^{3}\right)\end{array}$} \\
\hline & & & $\begin{array}{c}\text { Potential } \\
600 \mathrm{pa}\end{array}$ & Implemented & $\begin{array}{c}\text { Potential } \\
600 \mathrm{pa}\end{array}$ & $\begin{array}{c}\text { Implemented } \\
475 \mathrm{pa}\end{array}$ \\
\hline Humber & 200 & 11 & 289pa & $43.3 \mathrm{pa}$ & $291.5 \mathrm{pa}$ & $36 \mathrm{pa}$ \\
\hline Leicester & 200 & 10 & - & $114.2 \mathrm{pa}$ & - & - \\
\hline Aire and Calder & 400 & 11 & $1026 \mathrm{pa}$ & $623 \mathrm{pa}$ & - & 661pa \\
\hline $\begin{array}{l}\text { Hereford \& } \\
\text { Worcester }\end{array}$ & 17.6 & 37 & $2.7 \mathrm{pa}$ & - & $140 \mathrm{pa}$ & - \\
\hline WEFT & - & 8 & 166.2pa & $17.9 \mathrm{pa}$ & 166.2pa & $17.9 \mathrm{pa}$ \\
\hline West Midlands & - & 17 & - & $8.7 \mathrm{pa}$ & - & $4.8 \mathrm{pa}$ \\
\hline Catalyst & 1,000 & 14 & $1800 \mathrm{pa}$ & - & $1900 \mathrm{pa}$ & - \\
\hline
\end{tabular}

